Research Paper

\title{
G Protein-Coupled Estrogen Receptor 1 Inhibits Angiotensin II-Induced Cardiomyocyte Hypertrophy via the Regulation of PI3K-Akt-mTOR Signalling and Autophagy
}

\author{
Hui Pei ${ }^{14^{*}}$, Wei Wang ${ }^{*}$, Di Zhao ${ }^{3}$, Hongyan $\mathrm{Su}^{2}$, Guohai Su${ }^{1}$, Zhuo Zhao ${ }^{1 凶}$ \\ 1. Department of Cardiology, Jinan Central Hospital Affiliated with Shandong University, Shandong, China \\ 2. Department of Cardiology, Shandong Provincial Chest Hospital, Shandong, China \\ 3. Department of Cardiology, Affiliated Hospital of Shandong Academy of Medical Sciences, Shandong, China \\ 4. Taian Central Hospital, Taian City, Shandong, China \\ *H.P. and W.W. contributed equally to this work.
}

$\triangle$ Corresponding author: Zhuo Zhao, MD, PhD, Department of Cardiology, Jinan Central Hospital, Affiliated with Shandong University, 105 Jiefang Rd, Jinan 250014, Shandong Province, China. Tel: (+86) 531-82965022; Fax: (+86) 531-82506006; E-mail: zhaozhuo1230@163.com

(C) Ivyspring International Publisher. This is an open access article distributed under the terms of the Creative Commons Attribution (CC BY-NC) license (https://creativecommons.org/licenses/by-nc/4.0/). See http://ivyspring.com/terms for full terms and conditions.

Received: 2018.07.04; Accepted: 2018.09.14; Published: 2019.01.06

\begin{abstract}
Estrogen has been demonstrated to protect the heart against cardiac remodelling and heart failure in women. G protein-coupled estrogen receptor 1 (GPERI) is a recently discovered estrogen receptor (ER) that is expressed in various tissues. However, the mechanisms by which estrogen protects the heart, especially the roles played by ERs, are not clear. In this study, we explored the effect of GPERI activation on angiotensin II (Ang II)-induced cardiomyocyte hypertrophy and the involved signalling pathways and mechanisms. Our data demonstrated that GPER 1 is expressed in cardiomyocytes, a GPERI agonist, G1, attenuated Ang Il-induced cardiomyocyte hypertrophy and downregulated the mRNA expression levels of atrial natriuretic factor (ANF) and brain natriuretic peptide (BNP). Bioinformatics analysis revealed that five proteins, including RAPlgap, might be the key proteins involved in the attenuation of Ang II-induced cardiomyocyte hypertrophy by GPER 1 . $\mathrm{G} 1$ increased the protein level of $\mathrm{p}-\mathrm{Akt}, \mathrm{p}-70 \mathrm{~S} 6 \mathrm{~K} 1$ and p-mTOR but decreased p-4EBP1 expression. All these effects were inhibited by either G15 (a GPER I antagonist) or MK2206 (an inhibitor of Akt). Autophagy analysis showed that the LC3II/LC3I ratio was increased in Ang II-treated cells, and the increase was inhibited by $\mathrm{Gl}$ treatment. The effect of $\mathrm{Gl}$ on autophagy was blocked by treatment with G15, rapamycin, and MK2206. These results suggest that GPERI activation attenuates Ang II-induced cardiomyocyte hypertrophy by upregulating the PI3K-Akt-mTOR signalling pathway and inhibiting autophagy.
\end{abstract}

Key words: Angiotensin II (Ang II), cardiac hypertrophy, G protein-coupled estrogen receptor 1 (GPER1), Akt, autophagy

\section{Introduction}

The incidence of cardiac hypertrophy and heart failure is significantly increased in postmenopausal women compared with age-matched men and premenopausal women. A number of clinical and preclinical studies have shown that estrogen, as a sex hormone, might protect the heart against cardiac remodelling and heart failure in premenopausal women [1, 2]. The loss of endogenous estrogen has been believed to be a key factor that induces cardiovascular diseases in postmenopausal women. However, the cardioprotective effects of estrogen therapy in clinical trials are controversial [3,4]. It is 
critical in this field to further determine the mechanisms by which estrogen protects the heart in premenopausal women, especially the roles of individual estrogen receptors (ERs), including ERa, $E R \beta$, and $G$ protein-coupled estrogen receptor 1 (GPER1) in the heart, in order to generate more specific and effective hormone therapies for future clinical treatment.

GPER1, also known as G protein-coupled receptor 30 (GPR30), is a recently discovered estrogen receptor that is expressed in various tissues, including the cardiac tissue of humans and rodents. The activation of GPER1 by its specific agonist, G1, protects the heart from all types of stress, such as myocardial infarction and pressure overload, while GPER1 knockout impairs the structure and function of the heart in animal models [5]. Compared with the classical estrogen receptors ERa and ER $\beta$, which relatively slowly regulate gene transcription [6], GPER1 mainly acts through fast transduction mechanisms involving non-genomic estrogen signalling, such as cellular calcium mobilization, kinase activation and nitric oxide production [7]. In this study, we found that the PI3K-Akt-mTOR signalling pathway and autophagy in cardiomyocytes are regulated by GPER1 in an angiotensin II (Ang II)induced cardiomyocyte hypertrophy model. The results from tandem mass tag (TMT) protein mass spectrometry and bioinformatics analysis show that RAP1 protein might be one of the key proteins involved in the protective effects of GPER1.

\section{Materials and Methods}

\section{Ethics statement}

The animal experimental protocol complied with the Animal Management Rules of the Chinese Ministry of Health (Document No. 55, 2001) and was approved by the Animal Care and Use Committee of Shandong University. Wistar rats were purchased from the Animal Experimental Center of Shandong University. All animals were maintained at the Laboratory of Shandong University.

\section{Reagents}

Vehicle, Ang II, G1, G15 (a GPR30 antagonist), MK2206 [a protein kinase B (Akt) inhibitor], and rapamycin (an autophagy inducer) were purchased from Sigma-Aldrich (St. Louis, MO, USA). Antibodies against total and phosphorylated Akt (Akt and p-Akt, Ser473), total and phosphorylated mTOR (mTOR and p-mTOR, Ser2448), total and phosphorylated P70s6k1 (S6K1 and p-S6K1), total and phosphorylated 4EBP1 (4EBP and p-4EBP), LC3I and LC3II, andglyceraldehyde-3-phosphate dehydrogenase (GAPDH) were purchased from Cell Signalling Technology, Inc.
(Danvers, MA, USA).

\section{Neonatal cardiomyocyte isolation and culture}

Neonatal cardiomyocytes were isolated from the hearts of 2- to 4-day-old Wistar rats. Briefly, the hearts of neonatal rats were cut into $2-3 \mathrm{~mm}^{3}$ pieces and digested with type 2 collagenase and trypsin (Gibco-BRL Life Technologies, Rockville, MD) at $37^{\circ} \mathrm{C}$ for $10 \mathrm{~min}$. The cell suspension was centrifuged and filtered to remove fibroblasts, and cardiomyocytes were counted and seeded at $5 \times 10^{4}$ cells $/ \mathrm{cm}^{2}$ in 6 -well culture plates. Cells were then grown in complete Dulbecco's modified Eagle's medium (DMEM, Invitrogen) supplemented with $10 \%$ foetal calf serum, $1 \%$ penicillin and streptomycin and maintained in $95 \%$ air and $5 \% \mathrm{CO}_{2}$ at $37^{\circ} \mathrm{C}$. For each experiment, cells were starved for $12 \mathrm{~h}$ in DMEM without serum and washed once with phosphate-buffered saline (PBS) before they were used for experiments.

\section{TMT labelling and bioinformatics analysis}

Following digestion with $0.1 \%$ trypsin, the SDS-PAGE electrophoresis method was used to verify the quality of the samples to meet the requirements of subsequent tests. Protein samples were further enzymatically digested into peptides by FASP (Filter-aided sample preparation) method and peptides were quantified using Nano Drop 2000, and labelled according to the instructions of the Thermo Fisher Scientific TMT labelling kit. Samples were chromatographed and subjected to TMT quantitative proteomic analysis using a Q Exactive Plus (Thermo Fisher Scientific) high-resolution mass spectrometer. Liquid chromatography-mass spectrometry (LC/MS) data were identified and quantified using the Proteome Discoverer (version 2.1) software Suite and MASCOT 2.5 after selecting the key molecules and genes participating in the GPER1-mediated regulation of cardiac hypertrophy with a difference ratio (DR) $>1.2$ and $P<0.05$.

Database for annotation, visualization and integrated discovery (DAVID) provides analytic tools for gene ontology (GO) and pathway analyses. Bioinformatics analysis was based on the GO database (www.geneontology.org) and the Kyoto Encyclopedia of Genes and Genomes (KEGG) database.

\section{Cell treatments}

Ang II, G1, G15, MK2206 and rapamycin were dissolved in dimethyl sulfoxide (DMSO, SigmaAldrich). Five experiments were performed: (1) The cells were treated with different doses of Ang II (50, 100, and $250 \mathrm{nM}$ ) for 24 hours. (2) The cells were treated with $100 \mathrm{nM}$ of Ang II and different doses of G1 (10, 100, and $1000 \mathrm{nM}$ ) for 24 hours. (3) After 12 hours of culture in serum-free medium, the cells were 
treated with vehicle, Ang II, Ang II + G1, and Ang II + G1 + G15. (4) The cells were treated with vehicle, Ang II, Ang II + G1, and Ang II + G1 + MK2206. (5) Cells were treated with vehicle, Ang II, Ang II + G1, Ang II + G1 + G15, Ang II + G1 + MK2206, and Ang II + G1 + rapamycin. In experiment 3-5, the following doses of reagents were used: $100 \mathrm{nM}$ of Ang II, $1000 \mathrm{nM}$ of G1, $100 \mathrm{nM}$ of G15, $5 \mu \mathrm{M}$ of MK2206, and $100 \mathrm{nM}$ of rapamycin. After 24 hours of treatment, the cells were harvested for further analysis including real-time PCR, Western blot and immunofluorescence analysis.

\section{Immunofluorescence analysis and cell surface area measurements}

Following treatment, the cells cultured on chamber slides were fixed with ice-cold 100\% methanol for $10 \mathrm{~min}$ and incubated with a primary antibody against GPER1 (1:1000, Bioss Antibodies, Woburn, MA, USA) overnight at $4^{\circ} \mathrm{C}$. The cells were washed with PBS and then incubated with secondary IgG antibodies conjugated to Alexa 488 (1:500, Invitrogen, Carlsbad, CA, USA) for $45 \mathrm{~min}$ at room temperature. The nuclei were counterstained with 4',6-diamidino-2-phenylindole (DAPI). Excess antibody was removed by three washes with PBS, and cells were imaged with an Olympus BX51 microscope (Olympus, Tokyo, Japan). The cell surface area was determined using NIH ImageJ software (http:// rsbweb.nih.gov/ij/).

\section{Western blot analysis}

The cells were harvested and washed with PBS, and protein was extracted using cell lysis buffer (Beyotime Institute of Biotechnology, China). Equal amounts of protein $(50 \mu \mathrm{g})$ from each group were separated via $12 \%$ sodium dodecyl sulphatepolyacrylamide gel electrophoresis and transferred electrophoretically to polyvinylidene difluoride membranes (Millipore, Billerica, MA) using a wet transfer system (Bio-Rad, Hercules, CA). After being blocked with $5 \%$ non-fat milk for $2 \mathrm{~h}$, the membranes were incubated overnight at $4^{\circ} \mathrm{C}$ with primary antibodies against GAPDH, Akt and p-Akt, mTOR and p-mTOR, S6K1 and p-S6K1, 4EBP and p-4EBP, LC3I and LC3II (1:1000 dilution), followed by three washes with TBST. The membranes were subsequently incubated with secondary antibodies labelled with horseradish peroxidase [8] and visualized via enhanced chemiluminescence (Millipore). Protein levels were detected using an ImageQuant LAS 4000 chemiluminescence reader (GE) and analysed with MCID software (Imaging Research, Inc., Ontario, Canada).

\section{Real-time quantitative PCR (RT-qPCR)}

RT-qPCR was used to measure the mRNA levels of atrial natriuretic factor (ANF) and brain natriuretic peptide (BNP), which are biomarkers of cardiac hypertrophy, as well as GPER1 in the cells using a SYBR Green PCR kit (Qiagen, Inc., Valencia, California, USA), according to the manufacturer's protocol. The following primers were used for real-time PCR: 5'-CGT ATA CAG TGC GGT GTC CA-3' and 5'-GGT TGA CTT CCC CAG TCC AG-3' for ANF; 5'-AGC TGC TGG AGC TGA TAA GAG-3' and 5'-CTG CCC AAA GCA GCT TGA AC-3' for BNP; 5'-CCA TCA TCG GCC TGT GCT AT-3', and 5'-GAA GAC AAG GAC CAC TGC GA-3' for GPER1; and 5'-AAG AAG GTG GTG AAG CAG GC-3' and 5'-TCC ACC ACC CTG TTG CTG TA-3' for GAPDH. Amplification and detection were performed with the ABI7500 Sequence Detection System (Applied Biosystems, Foster City, CA). The final real-time PCR analysis results are presented as the ratio of the mRNA of interest to that of GAPDH, which was used as an internal control. The relative mRNA levels were calculated using the $2^{-\Delta \Delta C t}$ method.

\section{Statistical analysis}

The statistical analysis was performed using SPSS version 16.0 (SPSS, Inc., Chicago, IL, USA). The results are expressed as the mean \pm SEM. Statistical significance was determined by one-way ANOVA, followed by Tukey post hoc tests. A value of $P<0.05$ was considered statistically significant.

\section{Results}

\section{Ang II-induced cardiomyocyte hypertrophy}

Cardiomyocyte hypertrophy was determined by both the cell surface area and the mRNA expression levels of ANF and BNP, biomarkers for cardiomyocyte hypertrophy. As shown in Figure S1, the average cell surface area with the vehicle treatment was $1344 \pm 203 \mu^{2}$, while Ang II treatment at a dose of 50 $\mathrm{nmol} / \mathrm{L}, 100 \mathrm{nmol} / \mathrm{L}$, and $250 \mathrm{nmol} / \mathrm{L}$ increased the cell surface area to $1657 \pm 169 \mu^{2}, 2603 \pm 382 \mu \mathrm{m}^{2}$, and $3350 \pm 413 \mu \mathrm{m}^{2}$, respectively, ( $P<0.05$ vs vehicle). The real-time PCR results demonstrated that Ang II treatment significantly increased the mRNA expression of ANF and BNP in a concentrationdependent manner (Figure S1). An Ang II dose of 100 $\mathrm{nmol} / \mathrm{L}$ was selected for the treatment condition in subsequent experiments.

\section{GPERI expression in cardiomyocytes}

The expression of GPER1 in cardiomyocytes was detected by immunofluorescence staining, Western blot, and RT-qPCR. As shown in Figure 1, the immunofluorescence, Western blot and PCR analyses revealed that GPER1 was expressed in neonatal rat cardiomyocytes. Moreover, Ang II treatment increased the expression of GPER1, while treatment 
with G1 or G15 had no effect on the expression of GPER1 (Figure 1).

\section{GPER 1 activation attenuates Ang II-induced cardiomyocyte hypertrophy}

To determine whether GPER1 activation has an effect on Ang II-induced hypertrophy in neonatal cardiomyocytes, we treated cells with different concentrations of G1 $(10 \mathrm{nmol} / \mathrm{L}, 100 \mathrm{nmol} / \mathrm{L}$, and $1000 \mathrm{nmol} / \mathrm{L})$. Compared with the vehicle, Ang II

significantly increased the mRNA expression of ANF and BNP by more than three times $(P<0.05)$, while G1 treatment attenuated these increases in a dose-dependent manner (Figure 2A). A total of 1000 $\mathrm{nmol} / \mathrm{L}$ of G1 was used in the following experiments. The effects of G1 on the Ang II-induced increases in ANF and BNP were blocked by co-treatment with G15, a GPER1 antagonist (Figure 2B-C).
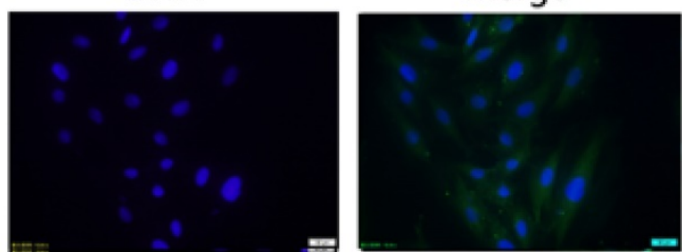

Angll
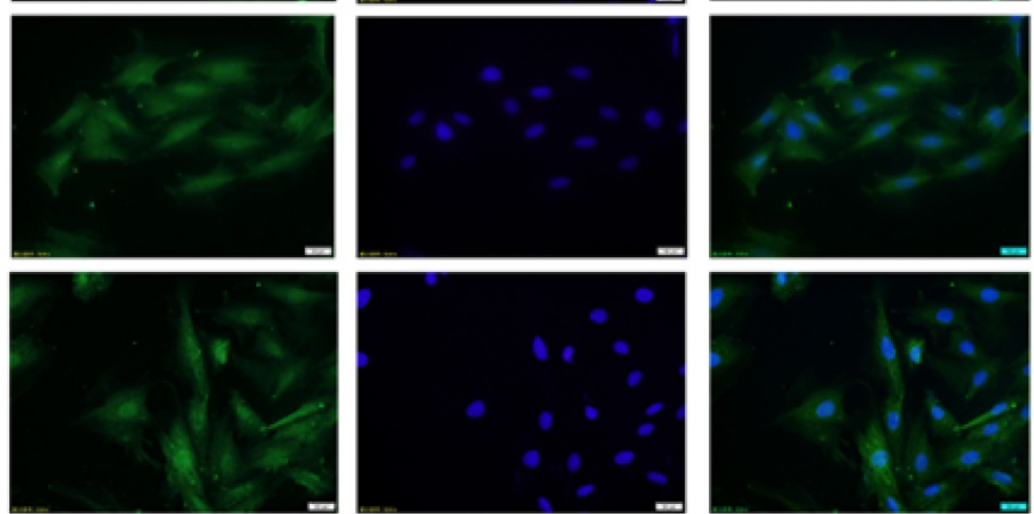

Angll+G1
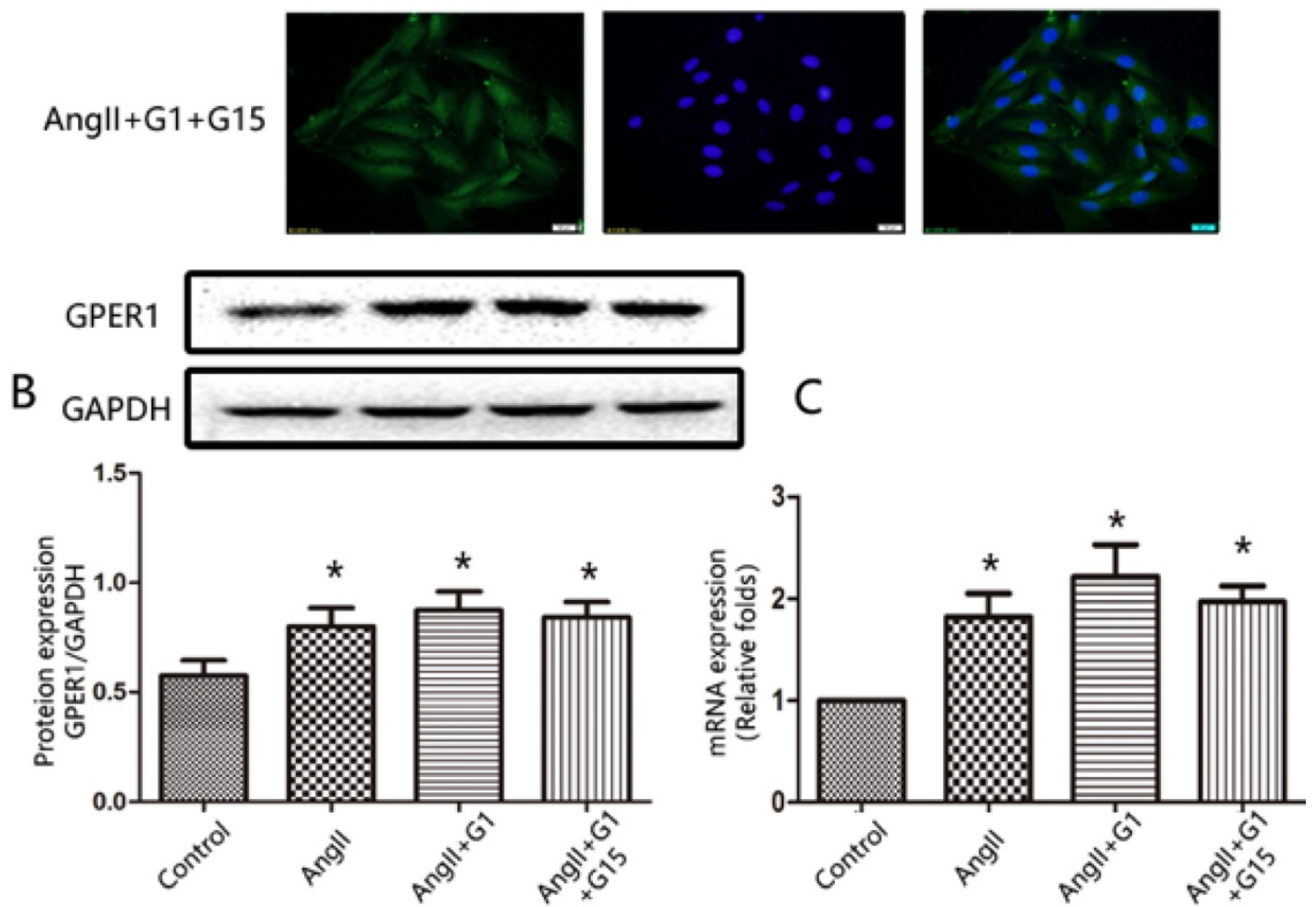

Figure 1. GPER1 expression in cardiomyocytes. (A) Immunofluorescence staining for GPER1, green (magnification $\times 400$ ). Scale bar 20 um. (B) Western blot and quantitative analysis of GPER1 expression. (C) GPER1 mRNA expression levels. Data are expressed as the mean \pm SEM ( $\mathrm{n}=3$ ). $* P<0.05$ versus control. G1: a GPER1 agonist, G15: GPR30 antagonist, Ang II: angiotensin II. 


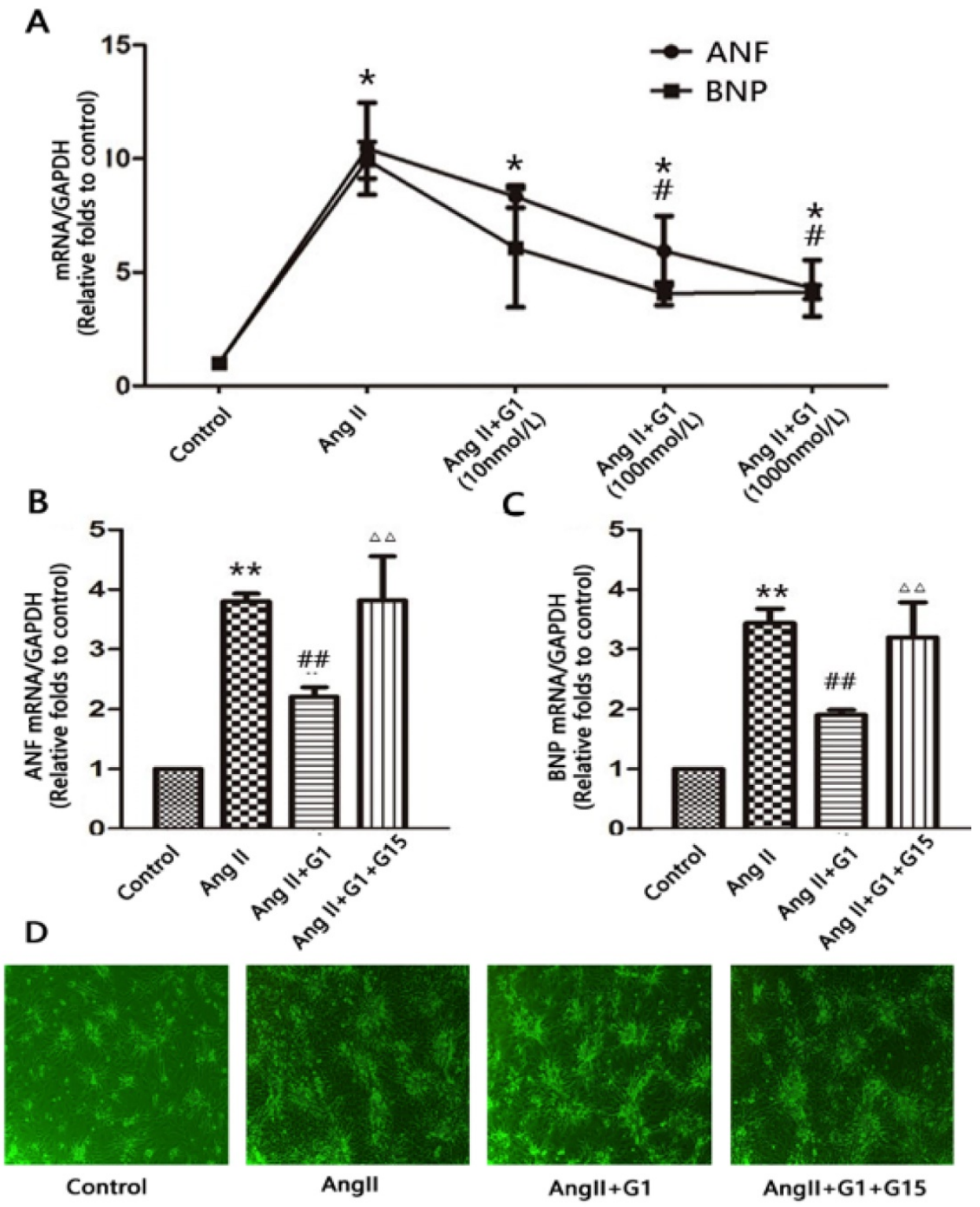

Figure 2. GPERI activation attenuates Ang II-induced cardiomyocyte hypertrophy. (A) ANF and BNP mRNA expression levels in different concentrations of G1. (B-C) ANF and BNP mRNA expression levels in four groups. (D) Microscope picture of myocardial cells. Data are expressed as the mean \pm SEM $(n=3) .{ }^{*} P<0.05$ versus control, ${ }^{* *} P<0.0$ I versus control, ${ }^{*} P<0.05$ versus Ang II, ${ }^{\#} P<0.0$ I versus Ang II, $\triangle \triangle P<0.01$ versus Ang II+G1. ANF: atrial natriuretic factor, BNP: brain natriuretic peptide, G1: a GPER1 agonist, G15: GPR30 antagonist, Ang II: angiotensin II.

\section{Protein mass spectrometry results from cardiomyocytes}

In this study, 7330 proteins and 62155 peptides were detected in cardiomyocytes treated with vehicle, Ang II alone, and Ang II + G1. Compared to the vehicle, Ang II significantly increased the expression of 52 proteins and decreased the expression of 1 protein (Table 1). Compared with the Ang II group, there were 24 upregulated proteins and 12 downregulated proteins in the Ang II + G1 group (Table 2, Figure 3A-B). By analysing the annotation of protein function, we found that there were five key proteins that were regulated by Ang II and inhibited by G1. These five proteins were Fam120b, RGD1562310,
Ctrb1, RAP1gap and Pag1 (Figure 3C and Figure S2).

The expression of RAP1gap protein, a GTPase-activating protein (GAP) for Rap1, was more than nine times higher in the Ang II group than the control group, and this increase was inhibited by G1 treatment $(P<0.05)$. We hypothesized that the effects of GPER1 on hypertrophic cardiomyocytes may be mediated by its downregulation of the RAP1gap gene. It has been reported that RAP1gap is involved in activation of the PI3K-Akt signalling pathway [9]. Therefore, the following experiments were performed to determine the role played by PI3K-Akt-mTOR signalling in the protective effects of GPER1 in cardiomyocytes with Ang II stimulation. 
Table 1. Summary of Ang II vs. control differences analysis data

\begin{tabular}{|c|c|c|c|c|}
\hline Accession & Gene Name & Description & Ratio & Pvalue \\
\hline Q5RJS3 & Fam96a & Family with sequence similarity 96 , member A OS=Rattus norvegicus GN=Fam96a PE=1 SV=1 & 2.043 & 0.043 \\
\hline F1M6B3 & RGD1563365 & Protein RGD1563365 OS=Rattus norvegicus GN=RGD1563365 PE=4 SV=3 & 1.820 & 0.021 \\
\hline Q6P6S5 & Wrb & Tail-anchored protein insertion receptor WRB OS=Rattus norvegicus $\mathrm{GN}=\mathrm{Wrb} \mathrm{PE}=2 \mathrm{SV}=1$ & 1.696 & 0.039 \\
\hline F1M298 & Fbxo18 & F-box only protein 18 (Predicted) OS=Rattus norvegicus GN=Fbxo18 PE=4 SV=2 & 1.640 & 0.018 \\
\hline D4AE88 & Fam120b & Protein Fam120b OS=Rattus norvegicus GN=Fam120b PE=1 SV=1 & 1.450 & 0.029 \\
\hline D3ZTN6 & RGD1562310 & Protein RGD1562310 OS=Rattus norvegicus GN=RGD1562310 PE=4 SV=1 & 1.429 & 0.010 \\
\hline Q6AYG7 & Nfatc2ip & NFATC2-interacting protein OS=Rattus norvegicus GN=Nfatc2ip PE=1 SV=1 & 1.399 & 0.017 \\
\hline Q66H19 & Srfbp1 & Serum response factor-binding protein $1 \mathrm{OS}=$ Rattus norvegicus $\mathrm{GN}=\mathrm{Srfbp} 1 \mathrm{PE}=1 \mathrm{SV}=1$ & 1.390 & 0.018 \\
\hline F1MA56 & Ctrb1 & Chymotrypsinogen B OS=Rattus norvegicus $\mathrm{GN}=\mathrm{Ctrb} 1 \mathrm{PE}=1 \mathrm{SV}=1$ & 1.361 & 0.007 \\
\hline A0A0G2K1E3 & Kmt2b & Protein $\mathrm{Kmt} 2 \mathrm{~b}$ OS=Rattus norvegicus $\mathrm{GN}=\mathrm{Kmt} 2 \mathrm{~b} \mathrm{PE}=1 \mathrm{SV}=1$ & 1.358 & 0.029 \\
\hline Q5U2X1 & Fbxo9 & F-box only protein $9 \mathrm{OS}=$ Rattus norvegicus $\mathrm{GN}=\mathrm{Fbxo} 9 \mathrm{PE}=1 \mathrm{SV}=1$ & 1.354 & 0.034 \\
\hline F1LV89 & Rap1gap & Protein Rap1gap OS=Rattus norvegicus GN=Rap1gap PE=1 SV=3 & 1.349 & 0.034 \\
\hline A0A0G2JWM4 & Foxj3 & Protein Foxj3 OS=Rattus norvegicus GN=Foxj3 PE=1 SV=1 & 1.345 & 0.036 \\
\hline B0BN78 & Taf7 & Protein Taf7 OS=Rattus norvegicus GN=Taf7 PE=1 SV=1 & 1.335 & 0.036 \\
\hline D3Z8B0 & Cox16 & Protein Cox16 OS=Rattus norvegicus GN=Cox16 PE=1 SV=1 & 1.327 & 0.040 \\
\hline Q06QA3 & ND4L & NADH-ubiquinone oxidoreductase chain $4 \mathrm{~L} \mathrm{OS=Rattus} \mathrm{norvegicus} \mathrm{GN=ND4L} \mathrm{PE=3} \mathrm{SV=1}$ & 1.321 & 0.020 \\
\hline A0A096MJM7 & Neurl1 & Neuralized-like (Drosophila) (Predicted), isoform CRA_b OS=Rattus norvegicus GN=Neurl1 PE=4 SV=1 & 1.321 & 0.027 \\
\hline D3ZLC6 & Mybl2 & Myeloblastosis oncogene-like 2 (Predicted) OS=Rattus norvegicus GN=Mybl2 PE=4 SV=2 & 1.308 & 0.041 \\
\hline B5DEP4 & Mrpl42 & $28 \mathrm{~S}$ ribosomal protein $\mathrm{L} 42$, mitochondrial OS=Rattus norvegicus $\mathrm{GN}=\mathrm{Mrpl} 42 \mathrm{PE}=1 \mathrm{SV}=1$ & 1.308 & 0.007 \\
\hline F1LWN1 & Ncoa7 & Protein Ncoa7 OS=Rattus norvegicus GN=Ncoa7 PE=1 SV=3 & 1.297 & 0.045 \\
\hline D3ZH92 & Klhl26 & Kelch-like 26 (Drosophila) (Predicted), isoform CRA_d OS=Rattus norvegicus GN=Klhl26 PE=4 SV=1 & 1.293 & 0.027 \\
\hline Q8CJ11 & Adgrg2 & Adhesion G-protein coupled receptor G2 OS=Rattus norvegicus GN=Adgrg2 PE=1 SV=1 & 1.288 & 0.001 \\
\hline Q5U2T7 & $\mathrm{Tfb} 2 \mathrm{~m}$ & Dimethyladenosine transferase 2 , mitochondrial OS=Rattus norvegicus $\mathrm{GN}=\mathrm{Tfb} 2 \mathrm{~m} \mathrm{PE}=2 \mathrm{SV}=1$ & 1.284 & 0.048 \\
\hline Q498U1 & Abcg314 & $\begin{array}{l}\text { Similar to ATP-binding cassette, sub-family G (WHITE), member } 3 \text { OS=Rattus norvegicus GN=Abcg314 PE=2 } \\
\mathrm{SV}=1\end{array}$ & 1.282 & 0.045 \\
\hline Q5XHX2 & Tprn & Taperin OS=Rattus norvegicus GN=Tprn PE=1 SV=2 & 1.279 & 0.031 \\
\hline A0A0G2K6T4 & Inpp5e & $72 \mathrm{kDa}$ inositol polyphosphate 5-phosphatase OS=Rattus norvegicus GN=Inpp5e PE=1 SV=1 & 1.273 & 0.038 \\
\hline O88422 & Galnt5 & Polypeptide N-acetylgalactosaminyltransferase $5 \mathrm{OS}=$ Rattus norvegicus GN=Galnt5 PE=2 SV=1 & 1.271 & 0.004 \\
\hline Q63312 & Phldb1 & $\begin{array}{l}\text { Pleckstrin homology-like domain family B member } 1 \text { (Fragment) OS=Rattus norvegicus GN=Phldb1 PE=1 } \\
\mathrm{SV}=2\end{array}$ & 1.267 & 0.030 \\
\hline A0A0G2K1R2 & $\mathrm{Bcl} 7 \mathrm{a}$ & Protein Bcl7a OS=Rattus norvegicus GN=Bcl7a PE=1 SV=1 & 1.264 & 0.043 \\
\hline F6Q5K7 & Mrps18b & Mitochondrial ribosomal protein S18B, isoform CRA_a OS=Rattus norvegicus GN=Mrps18b PE=1 SV=1 & 1.260 & 0.039 \\
\hline F1LNC3 & Phlpp1 & PH domain leucine-rich repeat protein phosphatase $1 \mathrm{OS}=$ Rattus norvegicus GN=Phlpp1 PE=1 SV=2 & 1.260 & 0.030 \\
\hline D3ZA66 & Pstpip2 & Protein Pstpip2 OS=Rattus norvegicus GN=Pstpip2 PE=1 SV=3 & 1.260 & 0.011 \\
\hline Q45QM2 & Gna12 & Guanine nucleotide binding protein alpha $12 \mathrm{OS}=$ Rattus norvegicus $\mathrm{GN}=\mathrm{G}$ na12 $\mathrm{PE}=2 \mathrm{SV}=1$ & 1.260 & 0.049 \\
\hline Q9R012 & Plk2 & Serine/threonine-protein kinase PLK2 OS=Rattus norvegicus GN=Plk2 PE=1 SV=1 & 1.260 & 0.003 \\
\hline Q4KLM4 & Klhl25 & Kelch-like protein $25 \mathrm{OS}=$ Rattus norvegicus GN=Klhl25 PE=2 SV=1 & 1.252 & 0.050 \\
\hline M0R5B1 & Shisa8 & Protein Shisa8 OS=Rattus norvegicus GN=Shisa8 PE=4 SV=1 & 1.251 & 0.014 \\
\hline A9UK92 & Siah1 & E3 ubiquitin-protein ligase $\mathrm{OS}=$ Rattus norvegicus $\mathrm{GN}=\mathrm{Siah} 1 \mathrm{PE}=2 \mathrm{SV}=1$ & 1.246 & 0.020 \\
\hline Q5PPG2 & Lgmn & Legumain OS=Rattus norvegicus GN=Lgmn PE=1 SV=1 & 1.235 & 0.049 \\
\hline Q5U2W6 & Ptov1 & Prostate tumor-overexpressed gene 1 protein homolog OS=Rattus norvegicus GN=Ptov1 PE=2 SV=1 & 1.232 & 0.025 \\
\hline G3V9M6 & Fbn1 & Fibrillin 1, isoform CRA_a OS=Rattus norvegicus GN=Fbn1 PE=1 SV=1 & 1.230 & 0.011 \\
\hline Q5RJT0 & & Ashwin OS=Rattus norvegicus PE=1 SV=1 & 1.226 & 0.027 \\
\hline F1M495 & Pla2r1 & Mannose receptor, $\mathrm{C}$ type 2 (Predicted) OS=Rattus norvegicus GN=Pla2r1 PE=4 SV=2 & 1.225 & 0.015 \\
\hline B1H275 & Wbscr22 & Protein Wbscr22 OS=Rattus norvegicus GN=Wbscr22 PE=1 SV=1 & 1.223 & 0.030 \\
\hline Q9JM80 & Pag1 & $\begin{array}{l}\text { Phosphoprotein associated with glycosphingolipid-enriched microdomains } 1 \mathrm{OS}=\text { Rattus norvegicus } \\
\text { GN=Pag1 } \mathrm{PE}=1 \mathrm{SV}=1\end{array}$ & 1.220 & 0.003 \\
\hline F1LQ66 & Prdm2 & $\mathrm{PR}$ domain zinc finger protein $2 \mathrm{OS}=$ Rattus norvegicus $\mathrm{GN}=\operatorname{Prdm} 2 \mathrm{PE}=1 \mathrm{SV}=1$ & 1.220 & 0.032 \\
\hline M0RDI3 & LOC100361475 & Protein LOC100361475 OS=Rattus norvegicus GN=LOC100361475 PE=4 SV=2 & 1.218 & 0.047 \\
\hline Q5PQN5 & Trim55 & Tripartite motif-containing protein $55 \mathrm{OS}=$ Rattus norvegicus $\mathrm{GN}=\operatorname{Trim} 55 \mathrm{PE}=1 \mathrm{SV}=1$ & 1.217 & 0.037 \\
\hline F1LZV1 & Kalrn & Kalirin OS=Rattus norvegicus GN=Kalrn PE=1 SV=3 & 1.215 & 0.001 \\
\hline Q6S396 & Plec & Plectin OS=Rattus norvegicus GN=Plec $\mathrm{PE}=1 \mathrm{SV}=1$ & 1.213 & 0.010 \\
\hline D3ZVF2 & Zfp295 & Protein Zfp295 OS=Rattus norvegicus GN=Zfp295 PE=1 SV=3 & 1.212 & 0.008 \\
\hline G3V667 & Itga6 & Integrin, alpha 6, isoform CRA_a OS=Rattus norvegicus GN=Itga6 PE=1 SV=1 & 1.203 & 0.029 \\
\hline A0A096Р6M7 & LOC102554637 & Protein LOC102554637 OS=Rattus norvegicus GN=LOC102554637 PE=3 SV=1 & 0.803 & 0.008 \\
\hline
\end{tabular}

Accession: Protein number in the protein sequence database (FASTA database); Description: Protein function described Uni Prot KB database; OS: Organism Name

[GN=Gene Name]; PE: Protein Existence; SV: Sequence Version; Ratio: The ratio of the mean value of the relative expression of the protein in Ang II group and Control.

\section{Gene ontology (GO) and Pathway analysis}

GO analysis, including biology process, molecular function, and cellular component analysis, were performed in Ang II-stimulated cardiomyocytes treated with vehicle or G1. Results from Biology Process analysis showed that G1 treatment mainly affected genes related to cellular process, single- organism process, single-organism cellular process, biological regulation, and organic substance metabolic process. According to molecular function analysis, G1 mainly affected protein binding-related genes. Cellular component analysis showed that G1 decreased gene expressions that are related to intracellular part, organelle, and cytoplasm 
component (Table S1).

As shown in Table S2, we have also performed KEGG Pathway analysis and found that the main signal pathways that G1 affected in cardiomyocytes were the following: pathways in cancer pathogenesis, PI3K-Akt signaling pathway, Alzheimer's disease, Huntington's disease, focal adhesion, carbon metabolism, non-alcoholic fatty liver disease (NAFLD), oxidative phosphorylation, and necroptosis. All the related signal pathways were activated by G1 treatment.

\section{GI activates PI3K-Akt-mTOR signalling in cardiomyocytes}

To further investigate the mechanisms by which the activation of GPER1 protects cardiomyocytes against stress caused by Ang II, Western blot was used to detect the potential signalling pathways involved. As shown in Figure 4, in cardiomyocytes, the protein expression levels of p-mTOR, p-Akt and p-S6K1 were significantly increased by Ang II, and these increases were further enhanced by G1 treatment. Ang II also increased p-4EBP, which was inhibited by G1. All of these effects of G1 were blocked by G15 treatment (Figure 4). To study the time course of Akt activation by G1, cells were treated with G1 for $0 \mathrm{~min}, 15 \mathrm{~min}, 30 \mathrm{~min}, 1 \mathrm{~h}, 2 \mathrm{~h}, 4 \mathrm{~h}$, and 8 h. As shown in Figure 4E, G1 induced Akt phosphorylation at the highest level after $30 \mathrm{~min}$ of treatment.
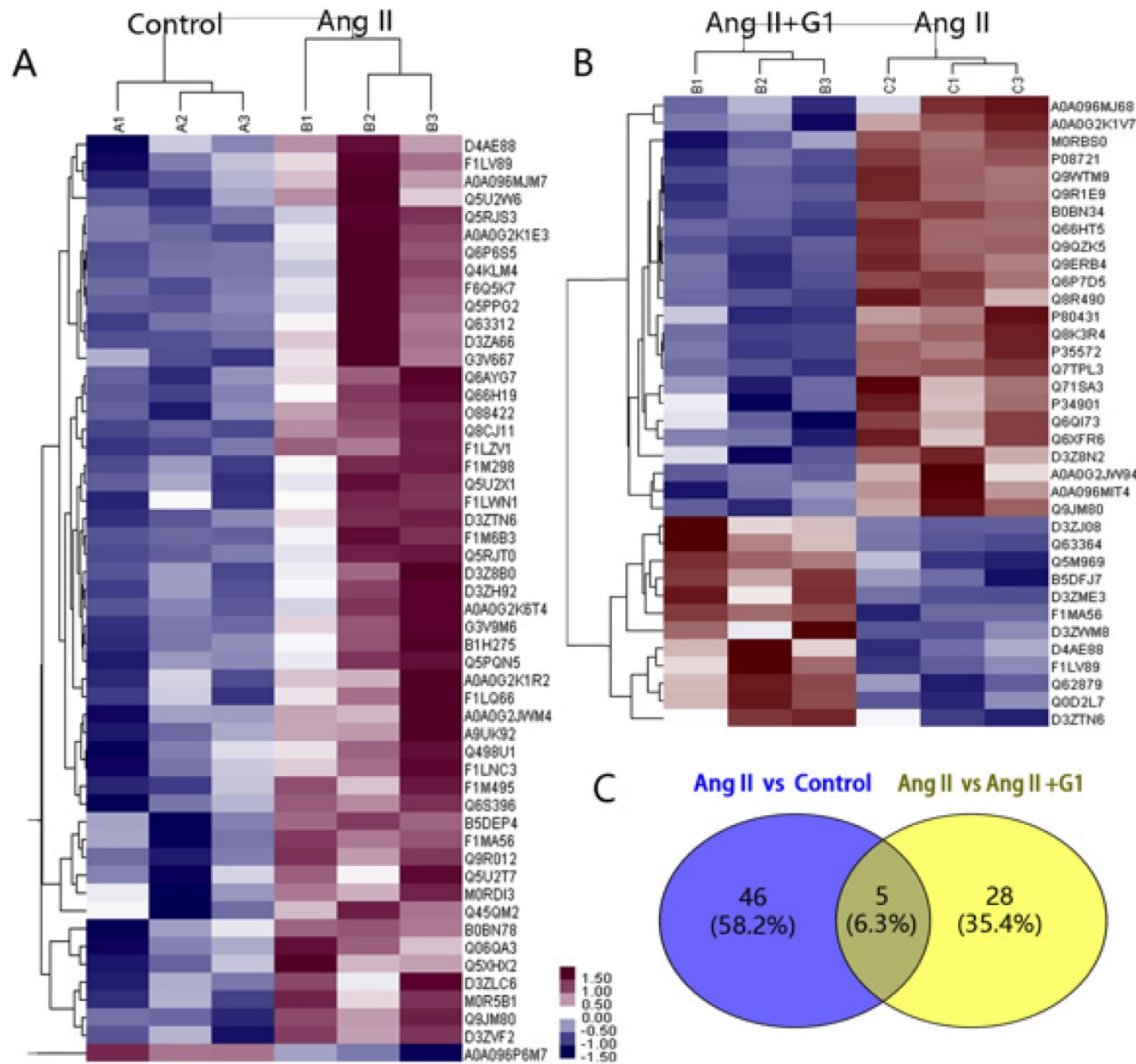

Figure 3. Protein mass spectrometry results from cardiomyocytes. (A) Cluster analysis result of Control and Ang II groups. (B) Cluster analysis result of Ang II+Gl group and Ang II groups. (C) Wayne diagram shows the difference analysis. Data are expressed as the mean $\pm S E M(n=3)$. $A 1, A 2, A 3$ : protein expression in three repeated control groups. B1, B2, B3: protein expression in three repeated Ang II-treated cells. C1, C2, C3: protein expression levels in three repeated Ang II+GI treated cells. Ang II: angiotensin II. Red indicates high expression level and green indicates low expression level. The darker color means the differences are more significant. 
Table 2. Summary of Angll+G1 vs. Ang II group differences analysis data

\begin{tabular}{|c|c|c|c|c|}
\hline Accession & Gene Name & Description & Ratio & P value \\
\hline Q9WTM9 & Cyr61 & CYR61 OS=Rattus norvegicus GN=Cyr61 PE=2 SV=1 & 1.590 & 0.001 \\
\hline Q8K3R4 & Adipoq & $30 \mathrm{kDa}$ adipocyte complement-related protein $\mathrm{OS}=$ Rattus norvegicus $\mathrm{GN}=\mathrm{Adipoq} \mathrm{PE}=1 \mathrm{SV}=1$ & 1.420 & 0.001 \\
\hline A0A096MJ68 & Slpi & Protein RGD1563818 OS=Rattus norvegicus GN=Slpi PE=4 SV=1 & 1.414 & 0.047 \\
\hline MORBS0 & Prelid3b & PRELI domain-containing protein 3B OS=Rattus norvegicus $G N=$ Prelid $3 b$ PE=1 SV=2 & 1.394 & 0.003 \\
\hline P08721 & Spp1 & Osteopontin OS=Rattus norvegicus $\mathrm{GN}=\mathrm{Spp} 1 \mathrm{PE}=1 \mathrm{SV}=2$ & 1.364 & 0.001 \\
\hline A0A0G2K1V7 & Sgcb & Protein $\mathrm{Sgcb}$ OS $=$ Rattus norvegicus $\mathrm{GN}=\mathrm{Sgcb} \mathrm{PE}=4 \mathrm{SV}=1$ & 1.354 & 0.009 \\
\hline Q66HT5 & Cyr61 & Cysteine rich protein $61 \mathrm{OS}=$ Rattus norvegicus $\mathrm{GN}=\mathrm{Cyr} 61 \mathrm{PE}=2 \mathrm{SV}=1$ & 1.337 & 0.001 \\
\hline Q9QZK5 & Htra1 & Serine protease HTRA1 OS=Rattus norvegicus $\mathrm{GN}=\mathrm{H}$ tra1 $\mathrm{PE}=2 \mathrm{SV}=1$ & 1.335 & 0.001 \\
\hline P80431 & Cox7b & Cytochrome $\mathrm{c}$ oxidase subunit $7 \mathrm{~B}$, mitochondrial $\mathrm{OS}=$ Rattus norvegicus $\mathrm{GN}=\mathrm{Cox} 7 \mathrm{~b} \mathrm{PE}=1 \mathrm{SV}=3$ & 1.330 & 0.013 \\
\hline P35572 & Igfbp6 & Insulin-like growth factor-binding protein $6 \mathrm{OS}=$ Rattus norvegicus $\mathrm{GN}=\mathrm{Igfbp} 6 \mathrm{PE}=1 \mathrm{SV}=1$ & 1.321 & 0.001 \\
\hline Q9ERB4 & Vcan & Versican core protein (Fragments) $\mathrm{OS}=$ Rattus norvegicus $\mathrm{GN}=\mathrm{V}$ can $\mathrm{PE}=2 \mathrm{SV}=2$ & 1.319 & 0.001 \\
\hline Q71SA3 & Thbs1 & Thrombospondin $1 \mathrm{OS}=$ Rattus norvegicus $\mathrm{GN}=$ Thbs $1 \mathrm{PE}=2 \mathrm{SV}=1$ & 1.290 & 0.014 \\
\hline P34901 & Sdc4 & Syndecan -4 OS=Rattus norvegicus $\mathrm{GN}=\mathrm{Sdc} 4 \mathrm{PE}=1 \mathrm{SV}=1$ & 1.254 & 0.035 \\
\hline D3Z8N2 & Rnf187 & E3 ubiquitin-protein ligase RNF187 OS=Rattus norvegicus GN=Rnf187 PE=1 SV=2 & 1.252 & 0.020 \\
\hline Q9R1E9 & Ctgf & Connective tissue growth factor $\mathrm{OS}=$ Rattus norvegicus $\mathrm{GN}=\mathrm{Ctgf} \mathrm{PE}=2 \mathrm{SV}=1$ & 1.248 & 0.001 \\
\hline A0A0G2JW94 & Clint1 & Protein Clint 1 OS=Rattus norvegicus $\mathrm{GN}=\mathrm{Clint} 1 \mathrm{PE}=1 \mathrm{SV}=1$ & 1.238 & 0.038 \\
\hline Q8R490 & Cdh13 & Cadherin 13 OS=Rattus norvegicus GN=Cdh13 PE=2 SV=1 & 1.237 & 0.004 \\
\hline A0A096MIT4 & $\mathrm{Il} 33$ & Interleukin-33 OS=Rattus norvegicus $\mathrm{GN}=\mathrm{I} 133 \mathrm{PE}=1 \mathrm{SV}=2$ & 1.237 & 0.014 \\
\hline Q9JM80 & Pag1 & $\begin{array}{l}\text { Phosphoprotein associated with glycosphingolipid-enriched microdomains } 1 \text { OS=Rattus norvegicus GN=Pag1 } \\
\mathrm{PE}=1 \mathrm{SV}=1\end{array}$ & 1.236 & 0.006 \\
\hline B0BN34 & Tnfaip6 & RCG37772 OS=Rattus norvegicus GN=Tnfaip6 PE=2 SV=1 & 1.227 & 0.001 \\
\hline Q6P7D5 & Mid1ip1 & Mid1-interacting protein $1 \mathrm{OS}=$ Rattus norvegicus $\mathrm{GN}=$ Mid1ip1 $\mathrm{PE}=1 \mathrm{SV}=1$ & 1.217 & 0.001 \\
\hline Q6QI73 & & LRRG00135 OS=Rattus norvegicus $\mathrm{PE}=2 \mathrm{SV}=1$ & 1.214 & 0.022 \\
\hline Q6XFR6 & Gypc & Glycophorin-C OS=Rattus norvegicus GN=Gypc PE=1 SV=1 & 1.205 & 0.008 \\
\hline Q7TPL3 & Kctd10 & $\begin{array}{l}\mathrm{BTB} / \mathrm{POZ} \text { domain-containing adapter for CUL3-mediated RhoA degradation protein } 3 \mathrm{OS}=\text { Rattus norvegicus } \\
\mathrm{GN}=\mathrm{Kctd} 10 \mathrm{PE}=1 \mathrm{SV}=1\end{array}$ & 1.203 & 0.004 \\
\hline D4AE88 & Fam120b & Protein Fam $120 \mathrm{~b}$ OS=Rattus norvegicus $\mathrm{GN}=$ Fam $120 \mathrm{~b}$ PE=1 SV=1 & 0.827 & 0.044 \\
\hline D3ZJ08 & Hist $2 \mathrm{~h} 3 \mathrm{c} 2$ & Histone $\mathrm{H} 3 \mathrm{OS}=$ Rattus norvegicus $\mathrm{GN}=\mathrm{Hist} 2 \mathrm{~h} 3 \mathrm{c} 2 \mathrm{PE}=1 \mathrm{SV}=1$ & 0.822 & 0.040 \\
\hline B5DFJ7 & Tmem9 & Protein Tmem 9 OS=Rattus norvegicus GN=Tmem $9 \mathrm{PE}=2 \mathrm{SV}=1$ & 0.817 & 0.006 \\
\hline Q63364 & Pja2 & E3 ubiquitin-protein ligase Praja-2 OS=Rattus norvegicus GN=Pja2 PE=2 SV=1 & 0.804 & 0.013 \\
\hline Q62879 & PPAR & PPAR delta protein OS=Rattus norvegicus $\mathrm{GN}=\mathrm{PPAR}$ delta $\mathrm{PE}=2 \mathrm{SV}=1$ & 0.785 & 0.009 \\
\hline Q5M969 & Nanp & N-acylneuraminate-9-phosphatase OS=Rattus norvegicus GN=Nanp PE=1 SV=1 & 0.780 & 0.005 \\
\hline D3ZWM8 & Elf4 & Protein Elf4 OS=Rattus norvegicus GN=Elf4 PE=1 SV=2 & 0.769 & 0.039 \\
\hline D3ZTN6 & RGD1562310 & Protein RGD1562310 OS=Rattus norvegicus GN=RGD1562310 PE=4 SV=1 & 0.761 & 0.045 \\
\hline F1LV89 & Rap1gap & Protein Rap1gap OS=Rattus norvegicus GN=Rap1gap PE=1 SV=3 & 0.744 & 0.017 \\
\hline Q0D2L7 & Cchcr1 & Hcr protein $\mathrm{OS}=$ Rattus norvegicus $\mathrm{GN}=\mathrm{Cch}$ cr $1 \mathrm{PE}=2 \mathrm{SV}=1$ & 0.738 & 0.007 \\
\hline D3ZME3 & & Uncharacterized protein $\mathrm{OS}=$ Rattus norvegicus $\mathrm{PE}=1 \mathrm{SV}=1$ & 0.675 & 0.011 \\
\hline F1MA56 & Ctrb1 & Chymotrypsinogen B OS=Rattus norvegicus $\mathrm{GN}=\mathrm{Ctrb} 1 \mathrm{PE}=1 \mathrm{SV}=1$ & 0.624 & 0.001 \\
\hline
\end{tabular}

Accession: Protein number in the protein sequence database (FASTA database); Description: Protein function described Uni Prot KB database; OS: OrganismName

[GN=Gene Name]; PE: Protein Existence; SV: Sequence Version; Ratio: The ratio of the mean value of the relative expression of the protein in Ang II+G1 group and Ang II group

\section{The Akt pathway is involved in GPER 1-mediated anti-cardiomyocyte hypertrophy}

The Akt-specific blocker MK2206 was used in this study to determine the involvement of the Akt pathway in the protective effects of GPER1 in cardiomyocytes with Ang II-induced stress. The PCR results show that MK2206 treatment inhibited the G1-induced decreases in ANF and BNP mRNA in hypertrophic cardiomyocytes stimulated by Ang II (Figure 5A-B). Moreover, Figure 5C shows that Akt inhibition by MK2206 blocked the G1-induced phosphorylation of Akt, mTOR, and S6K1 proteins.

\section{Involvement of cell autophagy in GPER 1-mediated anti-cardiomyocyte hypertrophy}

The LC3II/LC3I ratio was measured by Western blot to examine the autophagy activity in cardiomyo- cytes [10, 11]. As shown in Figure 6, LC3II/LC3I increased with Ang II stimulation, and this increase was inhibited by G1 treatment. However, the effect of G1 on LC3II/LC3I was attenuated by G15, MK2206, and an autophagy inducer, rapamycin (Figure 6).

\section{Discussion}

Endogenous estrogen plays an important role in the regulation of cardiovascular homeostasis in premenopausal women $[12,13]$, delaying the development of hypertension, coronary artery disease, cardiac hypertrophy, and heart failure compared to age-matched men. However, large randomized controlled clinical trials (WHI and HERS estrogen replacement trials) have not shown clear evidence of the cardioprotection of estrogen replacement therapy in postmenopausal women [14-16]. Moreover, chronic estrogen therapy increases the risk of cancer in the female reproductive system [12]. Therefore, it is critical to further investigate the 
mechanism of action of estrogen in the heart, especially the roles played by estrogen receptors, to generate more specific therapies with fewer side effects. The discovery of GPER1, which is expressed in various tissues, including the cardiac tissue, has opened a new door in this field of research. Previous studies have shown that the activation of GPER1 by its specific agonist, G1, protects the heart in both rat and mouse models with different stressors [17]. G1 was developed as a selective agonist of GPER to distinguish the estrogen effects mediated by GPER from those mediated by classic nuclear estrogen receptors (ERa and ER $\beta$ ). The original report showed that G1 was able to bind to GPER with high-affinity and did not bind to classic nuclear ERs and other 25 examined G-protein coupled receptors [18]. Since its first report in 2006, G1 has been wildly used to investigate the functions of GPER in various tissues and organs [19]. In the present study, we demonstrated that GPER1 activation by G1 protects cardiomyocytes against Ang II stimulation by
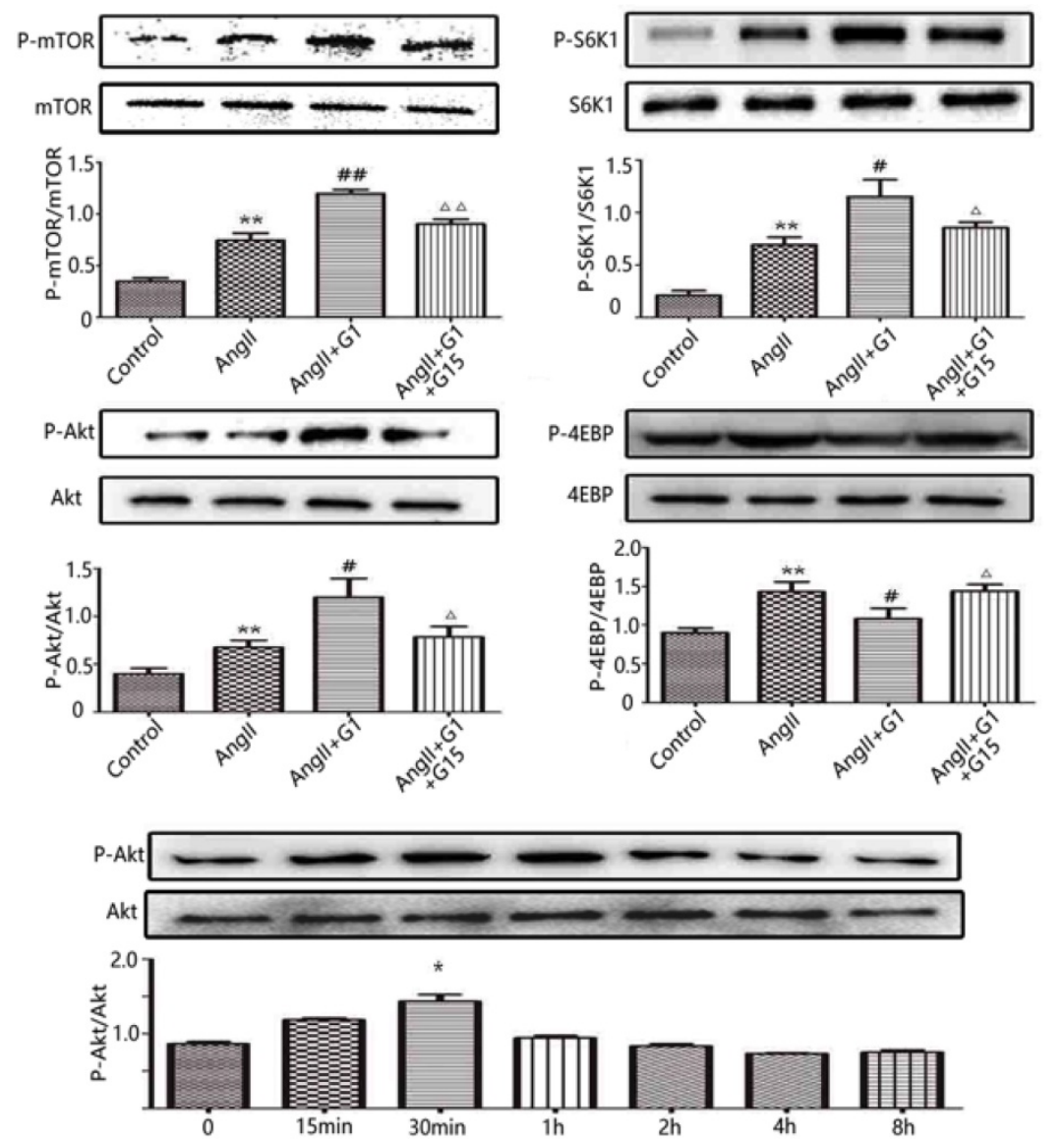

Figure 4. GI activates PI3K-Akt-mTOR signaling pathway in cardiomyocytes. (A-D) Western blot and quantitative analysis of cardiac mTOR, S6K1, Akt, 4EBP expression. (E) Expression of Akt protein in cardiomyocytes stimulated by $\mathrm{Gl}$ at different time. Data are expressed as the mean \pm SEM $(n=3) .{ }^{* *} P<0.01$ versus control, $\# P<0.05$ versus Ang II, \#P<0.0I versus Ang II, $\triangle P<0.05$ versus Ang II+G1, $\triangle \triangle P<0.01$ versus Ang II+G1. mTOR: mammalian target of rapamyein, S6K1: p-ribosomal protein S6 kinase, Akt: protein kinase B, 4EBP: p4E binding protein 1, G1: a GPER1 agonist, G15: GPR30 antagonist, Ang II: angiotensin II. regulating the Akt-mediated pathway and subsequently inhibiting autophagy.

By immunofluorescence staining, Western blot, and PCR, we demonstrated that GPER1 is expressed in neonatal rat cardiomyocytes. Moreover, Ang II increased GPER1 expression. While the mechanisms of increased GPER1 expression by Ang II are not clear, this result is consistent with the findings of De Francesco and colleagues showing that GPER1 expression is higher in the heart of spontaneously hypertensive rats (SHRs) versus control Wistar Kyoto (WKY) rats [20]. It has been demonstrated that GPER1 is located in the cell membrane and functions as an estrogen receptor [21, 22]. However, its subcellular locations, including the plasma membrane [23, 24], endoplasmic reticulum [25-27], and nuclei, remain controversial. Revankar's study showed that GPER1 on the endoplasmic reticulum may be involved in rapid intracellular non-genomic calcium mobilization by estrogen [25].

In vivo studies have demonstrated that the activation of GPER1 protects the heart from remodelling and heart failure against various stressors, such as Ang II stimulation, myocardial I/R injury, pressure overload, estrogen loss, and ageing [28]. However, the direct effects of GPER1 and the mechanisms of action in cardiomyocytes are still unclear. By measuring the cell surface area and biomarkers of hypertrophy, our study demonstrates that the activation of GPER1 has direct protective effects on cardiomyocytes against Ang II stimulation. In addition to cardiomyocytes, GPER1 has also been shown to have favourable effects on coronary artery smooth muscle cells (CASMCs) and endothelial cells against cardiac remodelling and heart failure [29-34]. It appears that GPER1 protects the heart against various stressors through different cell types in the heart.

To further investigate the mechanisms of the protective effect of GPER1 against Ang II-induced hypertrophy in cardiomyocytes, we performed TMT protein mass spectrometry to analyse the protein expression patterns in cells treated with the vehicle, Ang II, and Ang II + G1. Five key proteins, including RAP1gap, potentially related to GPER1's functions were found. RAP1gap is an important member of the small GTPase family in the Ras 
superfamily and is activated by different extracellular stimuli in various cell types. RAP1gap belongs to a family of proteins with gap function specific for RAP1/2, which also includes RAP1gap2,_SPA and E6TP1 $[35,36]$. GPER1 has also been reported to affect the Rap1 gene by regulating RAP1gap and subsequently activating the RhoA/Rho-kinase pathway, which is involved in protection against coronary artery disease [37]. Yu et al. [37] tested the effect of GPER activation on Rap1 activity in porcine CASMCs and observed that G1 markedly increased Rap1 activity; Rap1 siRNA transfection significantly inhibited G1-induced phosphorylation of RhoA at serine 188, further suggesting the role of Rap1 in GPER-mediated signaling. However, future studies are needed to determine the involvement of Rap1gap in the cardioprotective effects of GPER1 in animal models.

Cardiac hypertrophy is associated with activation of the Akt/mTOR signalling pathway. In our study, we found that G1 treatment activated the Akt-mediated signalling pathway, which is believed to be associated with cardiomyocyte growth,

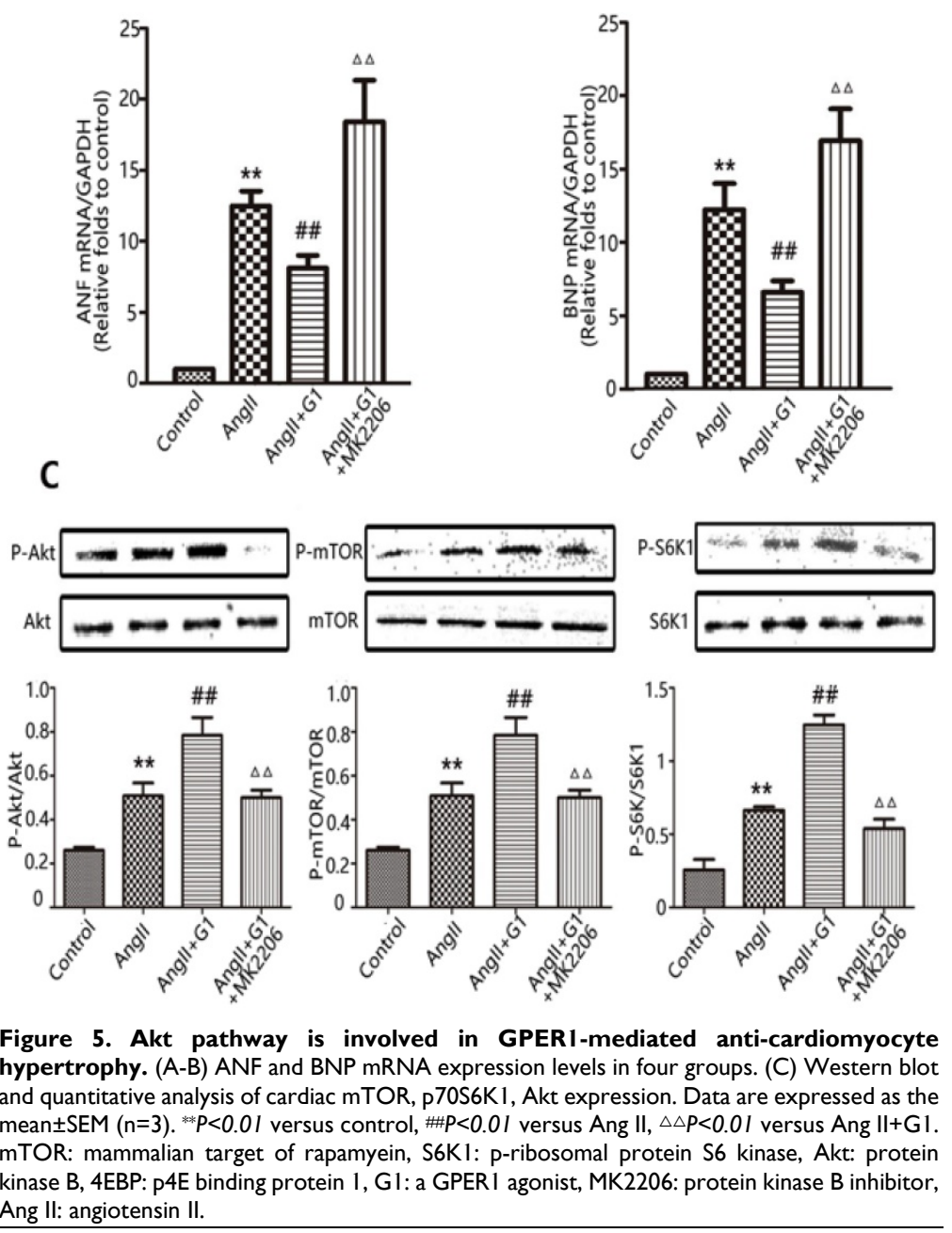

hypertrophy and survival. This finding regarding the regulation of Akt signaling pathway by GPER1 is consistent with other report in human periodontal ligament cells $[38,39]$. mTOR is an important protein molecule downstream from Akt-mediated signalling. It is an atypical serine/threonine protein kinase that affects gene transcription and protein translation and participates in the regulation of cell growth, proliferation and other processes. MTOR is involved in protein synthesis, immunity, cell migration and metabolism, apoptosis and autophagy [40]. Many pathways that mediate protein turnover depend on mTOR. Specifically, Akt/mTOR signalling is essential for the regulation of autophagy [41-43]. In the cardiovascular system, mTOR is believed to be an important negative regulator of autophagy [44]. Cardiac autophagy plays an important role in maintaining cell homeostasis, which at the basal level protects cells against various stimuli. However, excessive autophagy can cause autophagic cell death and accelerate the progression of heart disease [45]. Despite controversial conclusions about the effect of autophagy on hypertrophy, autophagy serves dual functions, and whether it acts adaptively or maladaptively depends on the degree of autophagy activation and the stage and severity of different diseases [46]. As shown in Figures 4 and 5, compared to Ang II treatment, the protein expression levels of p-mTOR, p-Akt and p-S6K1 were significantly increased by Ang II + G1 treatment. However, as shown in Figure 6, a significantly higher LC3II/LC3I ratio was observed in the Ang II group, and this increase was attenuated by G1. Moreover, rapamycin, G15 and MK2206 induced autophagy in cardiomyocytes. Our findings are supported by previous studies showing that G15 down-regulated the expression of Akt, cell cycle-associated and mitogenactivated protein kinases, and increased LC3B-II and autophagosome accumulation in human oral squamous carcinoma cells [47]. In mouse osteoblasts, 17 $\beta$-estradiol treatment also increases GPR30 expression and enhances mitochondrial autophagy through the GPR30 and ERK1/2 signaling pathways [48]. These findings suggest that excessive autophagy might mediate Ang II-induced cardiomyocyte hypertrophy, and G1-activated GPER1 attenuates Ang II-induced cardiomyocyte hypertrophy possibly by inhibiting autophagy via PI3K-Akt-mTOR signalling pathway up-regulation. 


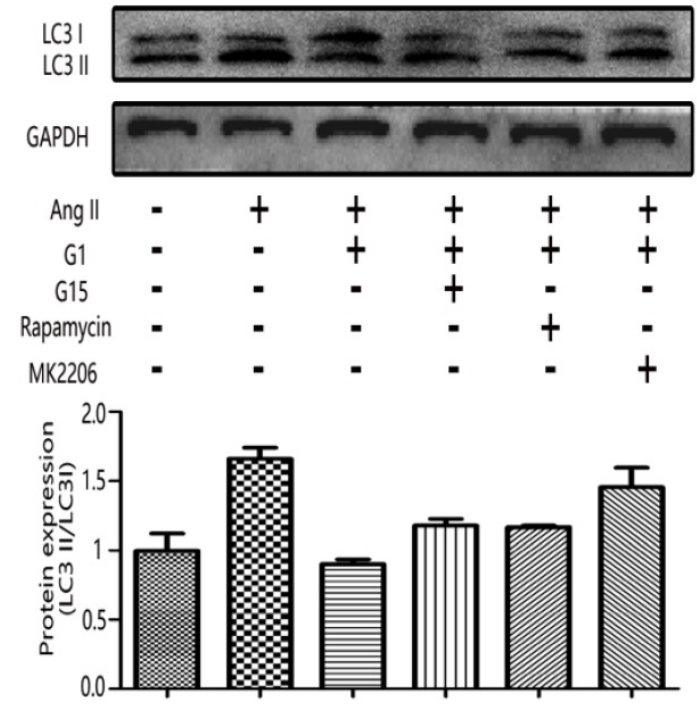

Figure 6. GPER I-mediated anti-cardiomyocyte hypertrophy triggers autophagy. Western blot and quantitative analysis of cardiac LC3I and LC3II expression. Data are expressed as the mean $\pm \operatorname{SEM}(n=3)$. ${ }^{*} P<0.01$ versus control, \#P<0.0I versus Ang II, $\triangle \triangle P<0.01$ versus Ang II+GI. GI: a GPERI agonist, G15: GPR30 antagonist, MK2206: protein kinase B inhibitor, Ang II: angiotensin II, microtubule-associated protein 1 light chain 3-II (LC3II), microtubule-associated protein 1 light chain 3-I (LC3I).

\section{Limitations and future studies}

Ang II-induced hypertrophy in neonatal cardiomyocyte has been commonly used as an in vitro model to study the mechanisms of cardiomyocyte hypertrophy [49-51]. However, the results from Ang II-induced hypertrophy in neonatal cardiomyocyte can be affected by the contamination of cardiac fibroblasts. Gray et al. [52] reported that Ang II stimulates myocyte hypertrophy might be due to the paracrine release of TGF- $\beta 1$ and endothelin- 1 from cardiac fibroblasts in a neonatal rat cell culture model. Future studies using adult cardiomyocytes are needed to confirm our findings in neonatal cardiomyocytes. We also realized another limitation of this study regarding the autophagy analysis. Cell autophagy was examined only by the method of Western blot, other methods, such as using electron microscopy, are planned in our future studies.

\section{Conclusions}

In summary, this study found that GPER1 activation attenuated Ang II-induced cardiomyocyte hypertrophy. This protective effect of GPER1 might be due to the upregulation of the PI3K-Akt-mTOR signalling pathway and the inhibition of autophagy in cardiomyocytes. Although numerous studies have demonstrated that GPER1 protects the heart from various stressors, the exact mechanism remains unclear. To our knowledge, there is no clinical study yet whether cardiac autophagy is involved in the development of postmenopausal heart diseases. The present study on the molecular mechanisms of GPER1 in cardiomyocytes improves our understanding of how estrogen protects the heart and provides potential pharmaceutical approaches targeting this new estrogen receptor-mediated pathway and cardiac autophagy.

\section{Supplementary Material}

Supplementary figures and tables. http://www.ijbs.com/v15p0081s1.pdf

\section{Acknowledgments}

This work was supported by grants from National Science Foundation of China (NO. 81670245).

\section{Author contributions}

H.P. and Z.Z. designed the experiments, H.P., W.W., D.Z., and H.S. performed the experiments. H.S., G.S., and Z.Z. analysed data and prepared the manuscript.

\section{Competing Interests}

The authors have declared that no competing interest exists.

\section{References}

[1] Mendelsohn ME. Protective effects of estrogen on the cardiovascular system. The American journal of cardiology. 2002;89(E):12-17; discussion 7E-8E.

[2] Vitale C, Fini M, Speziale G, Chierchia S. Gender differences in the cardiovascular effects of sex hormones. Fundamental \& clinical pharmacology. 2010;24:675-85.

[3] Filardo EJ, Quinn JA, Bland KI, Frackelton AR, Jr. Estrogen-induced activation of Erk-1 and Erk-2 requires the G protein-coupled receptor homolog, GPR30, and occurs via trans-activation of the epidermal growth factor receptor through release of HB-EGF. Molecular endocrinology. 2000;14:1649-60.

[4] Knowlton AA, Lee AR. Estrogen and the cardiovascular system. Pharmacology \& therapeutics. 2012;135:54-70.

[5] Meyer MR, Haas E, Prossnitz ER, Barton M. Non-genomic regulation of vascular cell function and growth by estrogen. Molecular and cellular endocrinology. 2009;308:9-16.

[6] Heldring N, Pike A, Andersson S, Matthews J, Cheng G, Hartman J, et al. Estrogen receptors: how do they signal and what are their targets. Physiological reviews. 2007:87:905-31.

[7] Prossnitz ER, Arterburn JB, Smith HO, Oprea TI, Sklar LA, Hathaway HJ. Estrogen signaling through the transmembrane $G$ protein-coupled receptor GPR30. Annual review of physiology. 2008;70:165-90.

[8] Fang Z, Tang Y, Jiao W, Xing Z, Guo Z, Wang W, et al. Nitidine chloride induces apoptosis and inhibits tumor cell proliferation via suppressing ERK signaling pathway in renal cancer. Food and chemical toxicology : an international journal published for the British Industrial Biological Research Association. 2014;66:210-6.

[9] Li W, Jin B, Cornelius LA, Zhou B, Fu X, Shang D, et al. Inhibitory effects of Rap1GAP overexpression on proliferation and migration of endothelial cells via ERK and Akt pathways. Journal of Huazhong University of Science and Technology Medical sciences = Hua zhong ke ji da xue xue bao Yi xue Ying De wen ban = Huazhong keji daxue xuebao Yixue Yingdewen ban. 2011;31:721-7.

[10] Bjorkoy G, Lamark T, Brech A, Outzen H, Perander M, Overvatn A, et al. p62/SQSTM1 forms protein aggregates degraded by autophagy and has a protective effect on huntingtin-induced cell death. The Journal of cell biology. 2005;171:603-14.

[11] Su H, Li J, Menon S, Liu J, Kumarapeli AR, Wei N, et al. Perturbation of cullin deneddylation via conditional Csn8 ablation impairs the ubiquitin-proteasome system and causes cardiomyocyte necrosis and dilated cardiomyopathy in mice. Circulation research. 2011;108:40-50.

[12] Baber RJ, Panay N, Fenton A, Group IMSW. 2016 IMS Recommendations on women's midlife health and menopause hormone therapy. Climacteric : the journal of the International Menopause Society. 2016;19:109-50. 
[13] Grady D, Rubin SM, Petitti DB, Fox CS, Black D, Ettinger B, et al. Hormone therapy to prevent disease and prolong life in postmenopausal women. Annals of internal medicine. 1992;117:1016-37.

[14] Rossouw JE, Anderson GL, Prentice RL, LaCroix AZ, Kooperberg C, Stefanick $\mathrm{ML}$, et al. Risks and benefits of estrogen plus progestin in healthy postmenopausal women: principal results From the Women's Health Initiative randomized controlled trial. Jama. 2002;288:321-33.

[15] Padula AM, Pressman AR, Vittinghoff E, Grady D, Neuhaus J, Ackerson L, et al. Placebo adherence and mortality in the Heart and Estrogen/Progestin Replacement Study. The American journal of medicine. 2012;125:804-10.

[16] Pardini D. [Hormone replacement therapy in menopause]. Arquivos brasileiros de endocrinologia e metabologia. 2014;58:172-81.

[17] Lee TM, Lin SZ, Chang NC. Both GPER and membrane oestrogen receptor-alpha activation protect ventricular remodelling in $17 \mathrm{beta}$ oestradiol-treated ovariectomized infarcted rats. Journal of cellular and molecular medicine. 2014;18:2454-65.

[18] Bologa CG, Revankar CM, Young SM, Edwards BS, Arterburn JB, Kiselyov AS, et al. Virtual and biomolecular screening converge on a selective agonist for GPR30. Nature chemical biology. 2006;2:207-12.

[19] Prossnitz ER, Barton M. The G-protein-coupled estrogen receptor GPER in health and disease. Nature reviews Endocrinology. 2011;7:715-26.

[20] De Francesco EM, Angelone T, Pasqua T, Pupo M, Cerra MC, Maggiolini M. GPER mediates cardiotropic effects in spontaneously hypertensive rat hearts. PloS one. 2013;8:e69322.

[21] Filardo E, Quinn J, Pang Y, Graeber C, Shaw S, Dong J, et al. Activation of the novel estrogen receptor $G$ protein-coupled receptor 30 (GPR30) at the plasma membrane. Endocrinology. 2007;148:3236-45.

[22] Funakoshi T, Yanai A, Shinoda K, Kawano MM, Mizukami Y. G protein-coupled receptor 30 is an estrogen receptor in the plasma membrane. Biochemical and biophysical research communications. 2006;346:904-10.

[23] Cheng SB, Graeber CT, Quinn JA, Filardo EJ. Retrograde transport of the transmembrane estrogen receptor, G-protein-coupled-receptor-30 (GPR30/GPER) from the plasma membrane towards the nucleus. Steroids. 2011;76:892-6.

[24] Sjostrom M, Hartman L, Grabau D, Fornander T, Malmstrom P, Nordenskjold $B$, et al. Lack of $G$ protein-coupled estrogen receptor (GPER) in the plasma membrane is associated with excellent long-term prognosis in breast cancer. Breast cancer research and treatment. 2014;145:61-71.

[25] Revankar CM, Cimino DF, Sklar LA, Arterburn JB, Prossnitz ER. A transmembrane intracellular estrogen receptor mediates rapid cell signaling. Science. 2005;307:1625-30.

[26] Otto C, Rohde-Schulz B, Schwarz G, Fuchs I, Klewer M, Brittain D, et al. G protein-coupled receptor 30 localizes to the endoplasmic reticulum and is not activated by estradiol. Endocrinology. 2008;149:4846-56.

[27] Koganti S, Snyder R, Gumaste U, Karamyan VT, Thekkumkara T. 2-methoxyestradiol binding of GPR30 down-regulates angiotensin AT(1) receptor. European journal of pharmacology. 2014;723:131-40.

[28] Wang $\mathrm{H}$, Jessup JA, Lin MS, Chagas C, Lindsey SH, Groban L. Activation of GPR30 attenuates diastolic dysfunction and left ventricle remodelling in oophorectomized mRen2.Lewis rats. Cardiovascular research. 2012;94:96-104.

[29] Han G, Li F, Yu X, White RE. GPER: a novel target for non-genomic estrogen action in the cardiovascular system. Pharmacological research. 2013;71:53-60.

[30] Deschamps AM, Murphy E. Activation of a novel estrogen receptor, GPER, is cardioprotective in male and female rats. American journal of physiology Heart and circulatory physiology. 2009;297:H1806-13.

[31] Lindsey SH, Cohen JA, Brosnihan KB, Gallagher PE, Chappell MC. Chronic treatment with the $\mathrm{G}$ protein-coupled receptor 30 agonist $\mathrm{G}-1$ decreases blood pressure in ovariectomized mRen2.Lewis rats. Endocrinology. 2009;150:3753-8.

[32] Yu X, Ma H, Barman SA, Liu AT, Sellers M, Stallone JN, et al. Activation of G protein-coupled estrogen receptor induces endothelium-independent relaxation of coronary artery smooth muscle. American journal of physiology Endocrinology and metabolism. 2011;301:E882-8.

[33] Meyer MR, Baretella O, Prossnitz ER, Barton M. Dilation of epicardial coronary arteries by the $\mathrm{G}$ protein-coupled estrogen receptor agonists $\mathrm{G}-1$ and ICI 182,780. Pharmacology. 2010;86:58-64.

[34] Han G, Ma H, Chintala R, Fulton DJ, Barman SA, White RE. Essential role of the 90-kilodalton heat shock protein in mediating nongenomic estrogen signaling in coronary artery smooth muscle. The Journal of pharmacology and experimental therapeutics. 2009;329:850-5.

[35] McLeod SJ, Shum AJ, Lee RL, Takei F, Gold MR. The Rap GTPases regulate integrin-mediated adhesion, cell spreading, actin polymerization, and Pyk2 tyrosine phosphorylation in B lymphocytes. The Journal of biological chemistry. 2004;279:12009-19.

[36] Singh L, Gao O, Kumar A, Gotoh T, Wazer DE, Band H, et al. The high-risk human papillomavirus type 16 E6 counters the GAP function of E6TP1 toward small Rap G proteins. Journal of virology. 2003;77:1614-20.

[37] Yu X, Zhang Q, Zhao Y, Schwarz BJ, Stallone JN, Heaps CL, et al. Activation of $G$ protein-coupled estrogen receptor 1 induces coronary artery relaxation via Epac/Rap1-mediated inhibition of RhoA/Rho kinase pathway in parallel with PKA. PloS one. 2017;12:e0173085.

[38] Fernandez-Campo L, Grande MT, Diego J, Fuentes-Calvo I, Macias-Nunez JF, Sanchez-Rodriguez A, et al. Effect of different antihypertensive treatments on Ras, MAPK and Akt activation in hypertension and diabetes. Clinical science. 2009;116:165-73
[39] Han Y, Wang X, Ma D, Wu X, Yang P, Zhang J. Ipriflavone promotes proliferation and osteogenic differentiation of periodontal ligament cells by activating GPR30/PI3K/AKT signaling pathway. Drug design, development and therapy. 2018;12:137-48.

[40] Lee CH, Inoki K, Guan KL. mTOR pathway as a target in tissue hypertrophy. Annual review of pharmacology and toxicology. 2007;47:443-67.

[41] Saiki S, Sasazawa Y, Imamichi Y, Kawajiri S, Fujimaki T, Tanida I, et al. Caffeine induces apoptosis by enhancement of autophagy via PI3K/Akt/mTOR/p70S6K inhibition. Autophagy. 2011;7:176-87.

[42] van der Vos KE, Eliasson P, Proikas-Cezanne T, Vervoort SJ, van Boxtel R, Putker $M$, et al. Modulation of glutamine metabolism by the PI(3)K-PKB-FOXO network regulates autophagy. Nature cell biology. 2012;14:829-37.

[43] Li Y, Zhu H, Zeng X, Fan J, Qian X, Wang S, et al. Suppression of autophagy enhanced growth inhibition and apoptosis of interferon-beta in human glioma cells. Molecular neurobiology. 2013;47:1000-10.

[44] Nakai A, Yamaguchi O, Takeda T, Higuchi Y, Hikoso S, Taniike M, et al. The role of autophagy in cardiomyocytes in the basal state and in response to hemodynamic stress. Nature medicine. 2007;13:619-24.

[45] Rifki OF, Hill JA. Cardiac autophagy: good with the bad. Journal of cardiovascular pharmacology. 2012;60:248-52.

[46] Li J, Cai Y. The dual effects of autophagy in myocardial hypertrophy. Acta cardiologica. 2015;70:493-8

[47] Bai LY, Weng JR, Hu JL, Wang D, Sargeant AM, Chiu CF. G15, a GPR30 antagonist, induces apoptosis and autophagy in human oral squamous carcinoma cells. Chemico-biological interactions. 2013;206:375-84.

[48] Sun X, Yang X, Zhao Y, Li Y, Guo L. Effects of 17beta-Estradiol on Mitophagy in the Murine MC3T3-E1 Osteoblast Cell Line is Mediated via G Protein-Coupled Estrogen Receptor and the ERK1/2 Signaling Pathway. Medical science monitor : international medical journal of experimental and clinical research. 2018;24:903-11.

[49] Miyata S, Haneda T. Hypertrophic growth of cultured neonatal rat heart cells mediated by type 1 angiotensin II receptor. The American journal of physiology. 1994;266:H2443-51.

[50] Watkins SJ, Borthwick GM, Oakenfull R, Robson A, Arthur HM. Angiotensin II-induced cardiomyocyte hypertrophy in vitro is TAK1-dependent and Smad2/3-independent. Hypertension research : official journal of the Japanese Society of Hypertension. 2012;35:393-8.

[51] Guo H, Liu B, Hou L, The E, Li G, Wang D, et al. The role of mAKAPbeta in the process of cardiomyocyte hypertrophy induced by angiotensin II. International journal of molecular medicine. 2015;35:1159-68.

[52] Gray MO, Long CS, Kalinyak JE, Li HT, Karliner JS. Angiotensin II stimulates cardiac myocyte hypertrophy via paracrine release of TGF-beta 1 and endothelin-1 from fibroblasts. Cardiovascular research. 1998;40:352-63. 